\title{
Female Sexual Arousal Disorder
}

National Cancer Institute

\section{Source}

National Cancer Institute. Female Sexual Arousal Disorder. NCI Thesaurus. Code C94339.

A disorder characterized by a recurrent or persistent inability to attain or maintain until completion of sexual activity an adequate physical response of sexual excitement, consisting of vasocongestion in the pelvis, vaginal lubrication and expansion, and swelling of the external genitalia. 